\title{
Eficiência de síntese microbiana e atividade enzimática em bovinos submetidos à suplementação com enzimas fibrolíticas ${ }^{1}$
}

\author{
Adriana de Souza Martins ${ }^{2}$, Paulo de Figueiredo Vieira ${ }^{3}$, Telma Teresinha Berchielli ${ }^{4}$, Ivanor \\ Nunes do Prado ${ }^{5}$, José Américo Soares Garcia ${ }^{6}$ \\ ${ }^{1}$ Parte da tese de Doutorado em Zootecnia apresentada pela primeira autora à FCAV/UNESP, financiada pelo CNPq e, parcialmente, pela \\ FUNDUNESP. \\ ${ }^{2}$ Cursos de Agronomia e Zootecnia do CESCAGE. Av. Carlos Cavalcanti, s/n CEP: 84030-000, Ponta Grossa - PR. \\ ${ }^{3}$ Curso de Zootecnia da Universidade José do Rosário Vellano - UNIFENAS, Rodovia MG 179, km 0, CEP: $37130-000$. \\ ${ }^{4}$ Departamento de Zootecnia da FCAVIUNESP, Pesquisador do CNPq. Rod. Carlos Tonnani km5, CEP:14870-000, Jaboticabal - SP. \\ ${ }^{5}$ Departamento de Zootecnia da UEM, Pesquisador do CNPq. Av. Colombo, 5790, CEP: 87020-900. \\ ${ }^{6}$ Departamento de Zootecnia da Universidade Federal de Tocantins, km112 - BR153, CEP: 77804-970, Araguaína-TO.
}

RESUMO - Avaliou-se o efeito da suplementação com enzimas fibrolíticas (celulase e xilanase) sobre a eficiência de síntese microbiana e a atividade enzimática da $\beta$-1,4-endoglucanase (celulase) em animais consumindo dietas contendo silagem de milho e feno de tifton 85 (Cynodon spp.) como volumoso. Oito bovinos com fístulas no rúmen e no duodeno foram distribuídos em dois quadrados latinos $4 \times 4$, em esquema fatorial $2 \times 2$ (duas fontes de volumoso e adição ou não de enzimas). $O$ complexo enzimático, proveniente de fonte comercial e extraído dos fungos Aspergillus niger e Trichoderma longibrachiatum, foi fornecido misturado à ração total na proporção de $12 \mathrm{~g} / \mathrm{animal} /$ dia. A adição de enzimas às dietas contendo silagem de milho e feno de tifton 85 aumentou a atividade da $\beta$-1,4-endoglucanase no fluido ruminal. Não houve efeito das enzimas sobre a eficiência de síntese de proteína microbiana, o fluxo de nitrogênio microbiano ( $\mathrm{N}$-mic) e nitrogênio não-amoniacal (NNA), com valores médios de 31,8 e 33,9 g de N/kg de MODR; 0,40 e 0,41 g de N/Mcal de EDR; 78,2 e 52,5 g/dia; 89,6 e 76,3 g/dia, respectivamente, para as dietas contendo silagem de milho e feno de tifton. A adição de enzimas fibrolíticas não influenciou os parâmetros ruminais de bovinos alimentados com feno e silagem de milho.

Palavras-chave: celulase, feno de tifton, ruminantes, silagem de milho

\section{Microbial synthesis efficiency and enzyme activity in cattle supplemented with fibrolytic enzymes}

\begin{abstract}
It was investigated the effects of fibrolytic enzymes (cellulase and xylanase) on the microbial protein synthesis efficiency and enzymatic activity of $\beta-1,4$-endoglucanase (cellulase) in animals receiving diets with corn silage and Tifton 85 hay (Cynodon spp.). Eight bovines fitted with rumen and duodenum cannulas were randomly assigned to two replicated $4 \times 4$ Latin squares with a $2 \times 2$ factorial arrangement of treatments (two forage sources with or without fibrolytic enzymes). The commercial enzymatic complex used in this trial was extracted from Aspergillus niger and Trichoderma longibrachiatum fungi. Each animal received $12 \mathrm{~g}$ /day of the enzymatic complex by mixing it in the ration. Inclusion of fibrolytic enzymes in the diet increased the $\beta-1,4-$ endoglucanase activity in the ruminal fluid of animals fed both forages. However, there was no effect of enzymes on efficiency of microbial protein synthesis that averaged 31.8 and $33.9 \mathrm{~g}$ of N/kg of OMDR and 0.40 and $0.41 \mathrm{~g}$ of N/Mcal of EDR, respectively, for corn silage and Tifton hay diets. Similarly, duodenal flows of microbial nitrogen (mic-N) and non ammonia nitrogen (NAN) did not differ and averaged 78.2 and $52.5 \mathrm{~g} /$ day and 89.6 and $76.3 \mathrm{~g} /$ day for corn silage and Tifton hay, respectively. Supplementation with fibrolytic enzymes had no effect on the ruminal parameters of cattle fed hay or corn silage.
\end{abstract}

Key Words: cellulase, corn silage, ruminants, Tifton hay

\section{Introdução}

A utilização de enzimas fibrolíticas isoladas de culturas de fungos na alimentação de ruminantes tem mostrado resultados satisfatórios, como aumentos na digestibilidade da matéria seca (MS) e da fibra em detergente neutro (FDN) (Hunt et al., 1995), na produção de leite e no teor de gordura do leite (Schingoethe et al., 1999) e no ganho de peso em bovinos (Beauchemin et al., 1995). Entretanto, essas respostas dependem de fatores como composição da dieta, método de aplicação e nível utilizado, especificidade ao substrato e tipo de complexo enzimático utilizado.

Em alguns estudos, observou-se que as enzimas fibrolíticas poderiam alterar a utilização dos alimentos pelos 
ruminantes, por meio do efeito direto sobre a fibra (Feng et al., 1996) e do aumento da digestão ruminal e/ou pósruminal (Hristov et al., 2000), havendo sinergismo com os microrganismos do rúmen. De fato, todos estes modos de ação estariam interligados, de modo que as alterações mediadas pelas enzimas antes do consumo refletiriam nas digestões ruminal e pós-ruminal dos nutrientes (McAllister et al., 2001).

Chesson (1993) considerou que a liberação no meio ruminal poderia expor as enzimas exógenas a condições desfavoráveis (temperatura, $\mathrm{pH}$ e condições físicas da digesta), podendo comprometer sua estrutura e, conseqüentemente, limitar sua atividade no substrato.

Em experimento para avaliar o efeito de diferentes métodos de aplicação das enzimas fibrolíticas nas características digestivas em novilhos, Lewis et al. (1996) não observaram efeito de enzimas fornecidas via cânula ruminal em comparação ao fornecimento direto sobre a forragem. Segundo os autores, as enzimas poderiam ter sido digeridas ou estar suspensas na fase fluida do conteúdo ruminal, sendo eliminadas do rúmen antes de um contato suficiente com as partículas de alimento para hidrólise.

As exigências protéicas dos ruminantes são atendidas mediante a absorção intestinal de aminoácidos provenientes, principalmente, da proteína microbiana sintetizada no rúmen e da proteína não degradada no rúmen (Valadares, 1997).

A síntese de proteína microbiana no rúmen pode ser afetada pela disponibilidade de carboidratos, amônia, peptídeos, aminoácidos, enxofre e ácidos graxos de cadeia ramificada, pela taxa de diluição ruminal, pelo $\mathrm{pH}$, pela taxa de fermentação e pela predação dentro do rúmen (Van Soest, 1994).

De acordo com Clark (1992), 59\% da proteína que chega ao intestino delgado é de origem microbiana e, segundo o NRC (1996), poderia suprir até $100 \%$ das exigências de proteína metabolizável de bovinos de corte.

Este trabalho foi realizado com o objetivo de determinar o efeito de enzimas fibrolíticas exógenas (celulase e xilanase) sobre a atividade enzimática da $\beta$-1,4-endoglucanase (celulase) e a eficiência de síntese microbiana em bovinos alimentados com silagem de milho e feno de tifton 85 .

\section{Material e Métodos}

O experimento foi desenvolvido no Setor de Avaliação de Alimentos do Departamento de Zootecnia da Faculdade de Ciências Agrárias e Veterinárias - UNESP, em JaboticabalSP, no período de novembro de 2001 a fevereiro de 2002.
As dietas estudadas foram: a) silagem de milho sem a adição de enzimas fibrolíticas (SMSE); b) silagem de milho com a adição de enzimas fibrolíticas (SMCE); c) feno de tifton 85 sem enzimas fibrolíticas (FESE); d) feno de tifton 85 com a adição de enzimas fibrolíticas (FECE). As dietas foram formuladas com base na ingestão de energia metabolizável fermentável e de proteína degradável no rúmen, segundo recomendações do AFRC (1995), e sua composição encontra-se descrita na Tabela 1.

Diariamente, foram fornecidos $40 \mathrm{~g}$ de suplemento mineral e vitamínico. A dieta completa (volumoso + concentrado) foi ofertada duas vezes ao dia.

As enzimas fibrolíticas utilizadas foram provenientes de fonte comercial (Fibrozyme) e extraídas dos fungos Aspergillus niger e Trichoderma longibrachiatum. O produto foi composto de celulase e xilanase e de um surfactante (extrato de Yucca echtigera), veículo com a função de aumentar o contato das enzimas com o substrato.

A atividade enzimática do Fibrozyme foi de aproximadamente 100 unidades de xilanase (UX) por grama do produto comercial (correspondente à quantidade de enzima requerida para liberar um micromol de xilose), obtida em temperatura de $39^{\circ} \mathrm{C} \mathrm{e} \mathrm{pH} \mathrm{4,0.} \mathrm{Os} \mathrm{teores} \mathrm{de} \mathrm{MS,} \mathrm{nitrogênio}$ total, FDN, FDA e hemicelulose do complexo enzimático foram de 90,21, 4,17, 20,64, 12,3 e 10,38\%, respectivamente. Foram fornecidos $12 \mathrm{~g}$ do produto/animal/dia, misturados ao sal mineral e à ração total.

Utilizaram-se oito bovinos com peso vivo médio de $340 \mathrm{~kg}$, providos de cânula no rúmen e no duodeno. $\mathrm{O}$ experimento foi dividido em quatro períodos de 20 dias, 14 para adaptação dos animais às dietas e seis para coleta do conteúdo ruminal e da digesta duodenal.

Amostras do conteúdo ruminal foram coletadas nos tempos: 1, 3, 5 e 7 horas após a alimentação, para determinação da atividade enzimática da $\beta$-1,4-endoglucanase. $O$ conteúdo foi filtrado em tecido de algodão, identificado por animal e por tratamento e congelado a $-20^{\circ} \mathrm{C}$ para posterior análise. As amostras foram processadas da seguinte forma: aproximadamente $5 \mathrm{~g}$ de cada amostra foram homogeneizados com $20 \mathrm{~mL}$ de tampão fosfato (pH 6,0; 0,2 M). As enzimas celulolíticas passaram por tratamento ultra-sônico (Branson Sonifier 250) sob gelo por 2 minutos a $70 \%$ output e foram recuperadas por centrifugação a $15.000 \mathrm{~g}$, durante 15 minutos a $4^{\circ} \mathrm{C}$.

Para o ensaio enzimático, $0,5 \mathrm{~mL}$ do sobrenadante (solução contendo enzimas) foi adicionado a $0,5 \mathrm{~mL}$ da solução de substrato (Azo-CM-Celulose 4M, Remazolbrillant Blue R - Megazyme) em tampão fosfato (pH 6,0), homogeneizado em vortex e incubado em banho-maria a 
Tabela 1 - Composição percentual e química das dietas (\%MS) Table 1 - Ingredient and chemical composition of diets (\% DM)

\begin{tabular}{|c|c|c|c|c|}
\hline \multirow[b]{2}{*}{$\begin{array}{l}\text { Ingrediente } \\
\text { Ingredient }\end{array}$} & \multicolumn{4}{|c|}{$\begin{array}{c}\text { Dieta }(\% \mathrm{MS}) \\
\text { Diet }(\% \mathrm{DM}) \\
\end{array}$} \\
\hline & $\begin{array}{l}\mathrm{SMSE}^{1} \\
\mathrm{CS}^{1}\end{array}$ & $\begin{array}{c}\mathrm{SMCE}^{2} \\
C S F E^{2}\end{array}$ & $\begin{array}{c}\mathrm{FESE}^{3} \\
T H^{3}\end{array}$ & $\begin{array}{r}\mathrm{FECE}^{4} \\
T H F E^{4}\end{array}$ \\
\hline $\begin{array}{l}\text { Silagem de milho } \\
\text { Corn silage }\end{array}$ & 69,93 & 69,92 & - & - \\
\hline $\begin{array}{l}\text { Feno de tifton } 85 \\
\text { Tifton } 85 \text { hay }\end{array}$ & - & - & 68,47 & 68,50 \\
\hline $\begin{array}{l}\text { Milho } \\
\text { Corn }\end{array}$ & 20,74 & 20,73 & 20,80 & 20,78 \\
\hline $\begin{array}{l}\text { Levedura } \\
\text { Yeast }\end{array}$ & 8,85 & 8,86 & 10,25 & 10,22 \\
\hline $\begin{array}{l}\text { Enzimas fibrolíticas } \\
\text { Fibrolytic enzymes }\end{array}$ & - & 0,13 & - & 0,13 \\
\hline $\begin{array}{l}\text { Sal mineral } \\
\text { Mineral salt } \\
\text { Nutriente } \\
\text { Nutrient }\end{array}$ & 0,50 & 0,51 & 0,50 & 0,51 \\
\hline $\begin{array}{l}\text { MS } \\
D M\end{array}$ & 48,48 & 48,57 & 89,22 & 89,25 \\
\hline $\begin{array}{l}\text { MO } \\
O M\end{array}$ & 87,46 & 87,42 & 83,77 & 83,74 \\
\hline $\begin{array}{l}\mathrm{PB} \\
C P\end{array}$ & 10,93 & 10,95 & 10,83 & 10,82 \\
\hline $\begin{array}{l}\text { FDN } \\
N D F\end{array}$ & 40,32 & 40,21 & 57,85 & 57,83 \\
\hline $\begin{array}{l}\text { FDA } \\
A D F\end{array}$ & 19,17 & 19,12 & 29,96 & 29,94 \\
\hline $\begin{array}{l}\text { Celulose } \\
\text { Cellulose }\end{array}$ & 15,58 & 15,53 & 24,04 & 24,03 \\
\hline $\begin{array}{l}\text { Hemicelulose } \\
\text { Hemicellulose }\end{array}$ & 21,15 & 21,09 & 27,89 & 27,88 \\
\hline
\end{tabular}

${ }^{1}$ Silagem de milho sem a adição de enzimas fibrolíticas; ${ }^{2}$ Silagem de milho com a adição de enzimas fibrolíticas; ${ }^{3}$ Feno de tifton sem a adição de enzimas fibrolíticas; ${ }^{4}$ Feno de tifton com a adição de enzimas fibrolíticas. ${ }^{1}$ Corn silage without fibrolytic enzymes; ${ }^{2}$ Corn silage with fibrolytic enzymes; ${ }^{3}$ Tifton hay without fibrolytic enzymes; ${ }^{4}$ Tifton hay with fibrolytic enzymes.

$39^{\circ} \mathrm{C}$ por 10 minutos. A reação foi paralisada e o substrato de alto peso molecular (insolúvel) foi precipitado pela adição de $2,5 \mathrm{~mL}$ de solução precipitadora $(200 \mathrm{~mL}$ de solução de acetato de zinco $-4 \mathrm{~g}$ e acetato de sódio trihidratado - $40 \mathrm{~g}$, pH 5,0, em $800 \mathrm{~mL}$ de etanol a 95\%). Depois de homogeneizados em vortex por 10 segundos, os tubos contendo as soluções foram mantidos em temperatura ambiente por 10 minutos e depois centrifugados a $1.000 \mathrm{~g}$ por 10 minutos. O sobrenadante foi, então, recuperado e a absorbância, lida em espectrofotômetro a $590 \mathrm{~nm}$ contra um branco, que consistiu da adição da solução precipitadora ao substrato antes da adição com a solução enzimática. Neste estudo, uma unidade de atividade enzimática foi definida arbitrariamente como a variação da absorbância a $590 \mathrm{~nm}$ durante 10 minutos, em $0,5 \mathrm{~mL}$ do extrato, a $39^{\circ} \mathrm{C}$.

Coletou-se também aproximadamente $1,5 \mathrm{~kg}$ de conteúdo ruminal às 3, 6 e 9 horas após a alimentação da manhã para isolamento das bactérias. Após cada coleta, o conteúdo foi misturado com $0,5 \mathrm{~L}$ de solução salina $1 \mathrm{~N}$, filtrado em tecido de algodão e armazenado em recipientes plásticos a $-20^{\circ} \mathrm{C}$ (Cecava et al., 1990).

Para estimativa do fluxo duodenal, foram coletados $200 \mathrm{~mL}$ de digesta duodenal, via cânula, durante quatro dias (quatro coletas por dia), conforme o seguinte esquema: $1^{\text {o }}$ dia: 8,16 e $24 \mathrm{~h} ; 2^{\circ}$ dia: 6,14 e $22 \mathrm{~h} ; 3^{\circ}$ dia: 4,12 e $20 \mathrm{~h}$; $4^{\circ}$ dia: 2,10 e $20 \mathrm{~h}$. As amostras foram identificadas e armazenadas a $-20^{\circ} \mathrm{C}$.

Ao final do experimento, as amostras de digesta ruminal e duodenal foram descongeladas, secas em estufa a $55^{\circ} \mathrm{C}$ durante 72 horas, moídas e misturadas em proporções iguais, com base no peso seco, para formar amostras compostas, por animal e por período de amostragem.

As amostras de líquido ruminal foram liofilizadas e analisadas, junto às de conteúdo duodenal, quanto aos teores de MS, MO e nitrogênio total (Silva, 1990). Para estimativa da biomassa de microrganismos, foram utilizadas as bases purinas como indicador microbiano, segundo metodologia descrita por Ushida et al. (1985).

$\mathrm{O}$ delineamento utilizado constituiu-se de dois quadrados latinos $4 \times 4$, em esquema fatorial $2 \times 2$. Os dados foram analisados considerando-se efeitos principais a fonte de volumoso (feno e silagem de milho) e os níveis de adição do complexo enzimático ( 0 e $12 \mathrm{~g} /$ animal/dia), bem como suas interações. A análise de variância e a comparação de médias pelo teste Tukey, a 5\% de significância, foram obtidas pelo PROC GLM DO SAS (1985).

\section{Resultados e Discussão}

A atividade enzimática da $\beta$-1,4-endoglucanase no líquido ruminal, de acordo com as dietas experimentais, é ilustrada na Figura 1.

A adição de enzimas fibrolíticas à silagem de milho e ao feno de tifton promoveu aumento na atividade da $\beta$-1,4endoglucanase no fluido ruminal nos primeiros tempos de incubação. Segundo Morgavi et al. (2000), no processo de degradação da silagem de milho, as celulases seriam mais limitantes que as xilanases, provavelmente em razão do menor tempo de geração de bactérias hemicelulolíticas. Wallace et al. (2001) avaliaram o efeito da suplementação enzimática sobre a digestão da fibra pelos microrganismos ruminais e relataram que a atividade da enzima $\beta$-1,4endoglucanase (celulase) limita a taxa de fermentação da silagem de milho no rúmen.

O complexo enzimático comercial utilizado era composto de celulase e xilanase, porém, não há informações quanto aos tipos de celulases e xilanases presentes neste produto. 


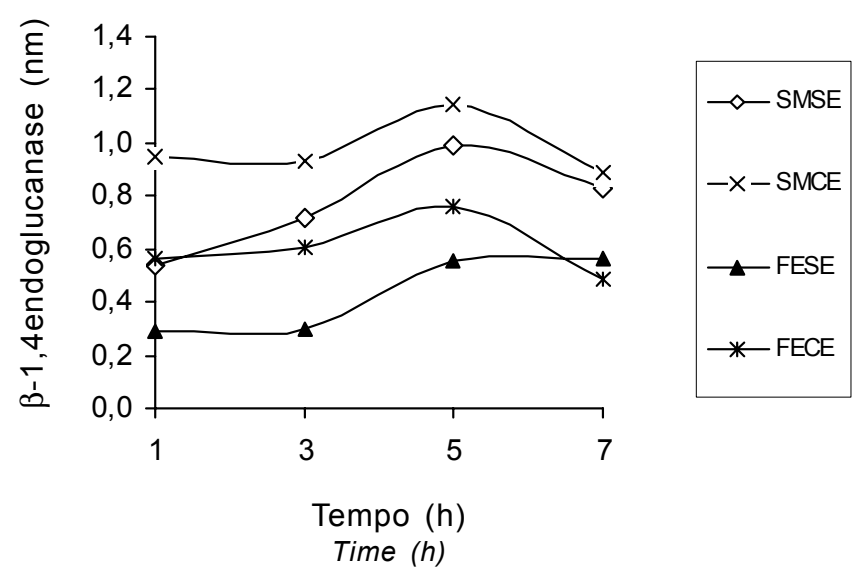

Figura 1 - Efeitos dos tempos de amostragem do fluido ruminal da silagem de milho sem enzimas fibrolíticas (SMSE), silagem de milho com enzimas fibrolíticas (SMCE), feno de tifton 85 sem enzimas fibrolíticas (FESE) e feno de tifton 85 com enzimas fibrolíticas (FECE) sobre a atividade enzimática da $\beta$-1,4-endoglucanase. Uma unidade de atividade foi arbitrariamente definida como a variação da absorbância/0,5 $\mathrm{mL}$ do extrato a $39^{\circ} \mathrm{C}$.

Figure 1 - Enzymatic activity of $\beta-1.4$-endoglucanase on the sample times of ruminal fluid of corn silage without fibrolytic enzymes (CS), corn silage with fibrolytic enzymes (CSFE), Tifton hay without fibrolytic enzymes (TH) and Tifton hay with fibrolytic enzymes (THFE). One activity unit was arbitrarily defined as absorbancy variation $/ 0.5 \mathrm{~mL}$ extract, at $39^{\circ} \mathrm{C}$

Além disso, embora tenha-se observado o efeito da suplementação enzimática sobre a atividade da $\beta$-1,4endoglucanase, não seria possível afirmar se esta enzima foi proveniente do próprio complexo enzimático ou se foi de origem microbiana. Michalet-Doreau et al. (2000) estudaram a atividade fibrolítica microbiana no rúmen e verificaram que a maior parte das enzimas microbianas foi secretada por microrganismos associados às partículas e que as espécies celulolíticas estavam presentes em maior proporção na fase sólida do conteúdo ruminal. Portanto, como a determinação da atividade desta enzima neste estudo foi realizada na porção líquida do fluido ruminal, é possível que o aumento da $\beta$-1,4-endoglucanase tenha sido proveniente do próprio complexo enzimático.

A atividade enzimática média da $\beta$-1,4-endoglucanase no fluido ruminal foi maior nas dietas contendo silagem de milho $(0,87)$, se comparadas àquelas contendo feno de tifton $(0,52)$, provavelmente em razão da maior exigência desta enzima para a degradação da silagem de milho, como verificado por Wallace et al. (2001), que, ao avaliarem a influência da suplementação com enzimas fibrolíticas na fermentação de silagens, observaram que essa enzima seria limitante na degradação da silagem de milho. Esses autores relataram que, em geral, os suplementos enzimáticos comerciais testados não apresentaram atividade suficiente da ß-1,4-endoglucanase para compensar a limitação sobre a degradação da silagem, principalmente quando aplicados diretamente no rúmen.

A atividade da $\beta$-1,4-endoglucanase foi determinada na fase líquida do conteúdo ruminal e, de acordo com McAllister et al. (2001), embora a adição de enzimas fibrolíticas aumente a atividade das xilanases e celulases no fluido ruminal, sua atividade nesta porção do rúmen representa apenas $30 \%$; o restante é de origem microbiana e está associado às partículas de alimento. Portanto, apesar do aumento verificado na atividade da $\beta$-1,4-endoglucanase, sua ocorrência não se deu na porção sólida do rúmen, onde existe maior concentração de enzimas celulolíticas que degradam potencialmente a fibra.

A composição das bactérias ruminais encontra-se na Tabela 2. Não houve efeito da interação $(P>0,05)$ fontes de volumoso $\times$ níveis de enzimas sobre as variáveis estudadas. O valor médio obtido para a porcentagem de matéria orgânica (MO) microbiana foi de $66,7 \%$, dentro da variação média de 61,2 a 94,2\%, referida por Valadares (1997), que utilizou a mesma metodologia para isolamento das bactérias. Entretanto, o teor médio de MO de 77,5\% relatado por Clark et al. (1992) foi superior ao obtido neste estudo.

De acordo com Valadares (1997), provavelmente a contaminação com solução salina durante o processo de isolamento das bactérias seja responsável por possíveis oscilações que causariam elevação dos teores de cinzas, contidos inicialmente na porcentagem de MO.

O teor médio de $\mathrm{N}$ total $(7,16 \%$ na MS) da dieta contendo feno de tifton foi semelhante ao valor médio de 7,1\% obtido por Valadares (1997) e ao de 7,7\% citado por Clark et al. (1992). Segundo Clark et al. (1992), as variações na composição das bactérias podem ser atribuídas às diferentes técnicas utilizadas para isolar e determinar a composição das bactérias ruminais e às próprias variações em sua composição.

Os consumos de MS e N, a matéria orgânica degradada no rúmen (MODR), a energia degradada no rúmen (EDR), os fluxos diários de $\mathrm{MO}, \mathrm{N}$ microbiano (N-mic) e $\mathrm{N}$ nãoamoniacal (NNA), o pH no duodeno e a eficiência de síntese microbiana, expressa em g de $\mathrm{N}$-mic/kg de MODR e em g $\mathrm{N}$-mic/MJ de EDR, são apresentados na Tabela 3.

Não houve efeito da interação $(\mathrm{P}>0,05)$ fontes de volumoso $\times$ níveis de enzima sobre os parâmetros avaliados. Da mesma forma, a adição de enzimas fibrolíticas não causou efeito $(\mathrm{P}>0,05)$ sobre estes parâmetros nas dietas contendo silagem de milho e feno de tifton 85 . Estes resultados estão de acordo com o observado por Beauchemin et al. (1999), que não notaram efeito da suplementação com enzimas em dietas contendo cevada sobre o fluxo de $\mathrm{N}$ microbiano no duodeno e sobre a MODR. Todavia, Caton et al. (1993), em 
Tabela 2 - Teores de MS, MO e $\mathrm{N}$ total (\% na MS) e estimativa de ácido ribonucléico (RNA) das bactérias isoladas do rúmen Table 2 - Levels of MS, OM, and total N (\% DM) and ribonucleid acid (RNA) estimate of isolated bacteria from the rumen

\begin{tabular}{|c|c|c|c|c|c|c|c|c|}
\hline \multirow{3}{*}{$\begin{array}{l}\text { Volumoso } \\
\text { Roughage } \\
\text { Enzima }\end{array}$} & \multicolumn{4}{|c|}{$\begin{array}{c}\text { Efeitos principais } \\
\text { Main effects }\end{array}$} & \multicolumn{4}{|c|}{$\begin{array}{l}\text { Média } \\
\text { Mean }\end{array}$} \\
\hline & \multicolumn{2}{|c|}{$\begin{array}{l}\text { SM } \\
C S\end{array}$} & \multicolumn{2}{|c|}{$\begin{array}{l}\mathrm{FE} \\
T H\end{array}$} & \multicolumn{2}{|c|}{$\begin{array}{l}\text { Volumoso } \\
\text { Roughage }\end{array}$} & \multicolumn{2}{|c|}{$\begin{array}{l}\text { Enzima } \\
\text { Enzyme }\end{array}$} \\
\hline & $\mathrm{SE}$ & $\mathrm{CE}$ & $\mathrm{SE}$ & $\mathrm{CE}$ & SM & $\mathrm{FE}$ & $\mathrm{SE}$ & $\mathrm{CE}$ \\
\hline Enzyme & $-E$ & $+E$ & $-E$ & $+E$ & $C S$ & $T H$ & $-E$ & $+E$ \\
\hline \multicolumn{9}{|l|}{$\begin{array}{l}\text { Parâmetro } \\
\text { Parameter }\end{array}$} \\
\hline MS (\%) (DM, \%) & 88,35 & 87,84 & 88,95 & 88,20 & $88,09 \mathrm{~A}$ & $88,57 \mathrm{~A}$ & $88,65 \mathrm{a}$ & $88,02 \mathrm{a}$ \\
\hline MO (\%) (OM, \%) & 67,92 & 67,07 & 66,32 & 65,42 & $67,25 \mathrm{~A}$ & $65,87 \mathrm{~A}$ & $67,07 \mathrm{a}$ & $66,04 a$ \\
\hline $\mathrm{N}$ total $(\%)$ (Total $N, \%)$ & 6,41 & 6,77 & 7,10 & 7,21 & $6,59 \mathrm{~A}$ & $7,16 \mathrm{~A}$ & $6,73 \mathrm{a}$ & $6,94 \mathrm{a}$ \\
\hline RNA (\%) (RNA, \%) & 5,73 & 6,86 & 7,19 & 7,77 & $6,30 \mathrm{~A}$ & $7,48 \mathrm{~A}$ & $6,46 \mathrm{a}$ & $7,32 \mathrm{a}$ \\
\hline
\end{tabular}

$\mathrm{SM}=$ silagem de milho; $\mathrm{FE}=$ feno de tifton; $\mathrm{SE}=$ sem adição de enzimas; $\mathrm{CE}=$ com adição de enzimas.

Médias seguidas de letras diferentes na mesma linha, maiúsculas para as fontes de volumoso (silagem de milho e feno de tifton) e minúsculas para os níveis de enzima ( 0 e $12 \mathrm{~g} /$ animal/dia), diferem $(P<0,05)$ pelo teste Tukey.

$C S=$ corn silage; $T H=$ Tifton hay; $-E=$ without enzyme; $+E=$ with enzyme .

Means followed by different letters in a row, capital letters to each roughage (corn silage and Tifton hay) and small letters to each to enzyme level ( 0 and $12 \mathrm{~g} / a n i m a l / d a y)$, differ $(P<0.05)$ by Tukey test.

Tabela 3 - Valores médios de ingestão de MS, N, MO degradada no rúmen (MODR), energia degradada no rúmen (EDR), fluxo duodenal de $\mathrm{MO}(\mathrm{MO}), \mathrm{N}$ microbiano (N-mic), nitrogênio não-amoniacal (NNA), pH duodenal e eficiência microbiana (eficiência mic.) das dietas experimentais

Table 3 - Means values of intakes of DM, N, OM degraded in the rumen (OMDR), energy degraded in the rumen (EDR), duodenum flow of organic matter $(\mathrm{OM})$, microbial nitrogen ( $\mathrm{N}-\mathrm{mic}$ ) and non amoniacal nitrogen (NAN), duodenum $\mathrm{pH}$ and microbial efficiency of the experimental diets

\begin{tabular}{|c|c|c|c|c|c|c|c|c|}
\hline \multirow{3}{*}{$\begin{array}{l}\text { Volumoso } \\
\text { Roughage } \\
\text { Enzima }\end{array}$} & \multicolumn{4}{|c|}{$\begin{array}{c}\text { Efeitos principais } \\
\text { Main effects }\end{array}$} & \multicolumn{4}{|c|}{$\begin{array}{l}\text { Média } \\
\text { Mean }\end{array}$} \\
\hline & \multicolumn{2}{|c|}{$\begin{array}{l}\mathrm{SM} \\
C S\end{array}$} & \multicolumn{2}{|c|}{$\begin{array}{l}\mathrm{FE} \\
T H\end{array}$} & \multicolumn{2}{|c|}{$\begin{array}{l}\text { Volumoso } \\
\text { Roughage }\end{array}$} & \multicolumn{2}{|c|}{$\begin{array}{l}\text { Enzima } \\
\text { Enzyme }\end{array}$} \\
\hline & SE & $\mathrm{CE}$ & SE & $\mathrm{CE}$ & SM & $\mathrm{FE}$ & SE & $\mathrm{CE}$ \\
\hline Enzyme & $-E$ & $+E$ & $-E$ & $+E$ & CS & $T H$ & $-E$ & $+E$ \\
\hline \multicolumn{9}{|l|}{$\begin{array}{l}\text { Parâmetro } \\
\text { Parameter }\end{array}$} \\
\hline $\begin{array}{l}\text { MS ingerida }{ }^{1} \\
D M \text { intake }^{1}\end{array}$ & 6,0 & 6,1 & 4,5 & 4,9 & $6,1 \mathrm{~A}$ & $4,7 \mathrm{~A}$ & $5,3 \mathrm{a}$ & $5,5 \mathrm{a}$ \\
\hline $\begin{array}{l}\mathrm{N} \text { ingerido }{ }^{2} \\
N \text { intake }\end{array}$ & 108,3 & 108,2 & 83,0 & 87,8 & $108,3 \mathrm{~A}$ & $85,4 \mathrm{~B}$ & $95,7 \mathrm{a}$ & $98,0 \mathrm{a}$ \\
\hline $\begin{array}{l}M_{O D R^{2}} \\
O M D R^{2}\end{array}$ & 2594,6 & 2630,3 & 1459,1 & 1647,9 & $2556,6 \mathrm{~A}$ & $1553,5 \mathrm{~B}$ & $2026,9 a$ & $2083,2 \mathrm{a}$ \\
\hline $\begin{array}{l}\mathrm{EDR}^{3} \\
E D R^{3}\end{array}$ & 11,9 & 11,5 & 7,1 & 7,9 & $11,7 \mathrm{~A}$ & $7,5 \mathrm{~B}$ & $9,5 \mathrm{a}$ & $9,7 \mathrm{a}$ \\
\hline \multicolumn{9}{|l|}{$\begin{array}{l}\text { Fluxo duodenal } \\
\text { Duodenum flow }\end{array}$} \\
\hline $\begin{array}{l}\mathrm{MO}^{2}(\mathrm{OM}) \\
\mathrm{N} \text { total }{ }^{2}(\mathrm{~N} \text { total }) \\
\mathrm{N} \text {-mic } \\
\mathrm{NNA}^{2}(\mathrm{NAN}) \\
\mathrm{pH} \text { no duodeno } \\
\mathrm{pH} \text { in duodenum }\end{array}$ & $\begin{array}{r}2729,3 \\
95,7 \\
83,9 \\
89,4 \\
2,4\end{array}$ & $\begin{array}{c}2687,2 \\
94,93 \\
72,4 \\
89,6 \\
2,5\end{array}$ & $\begin{array}{r}2361,9 \\
80,0 \\
54,9 \\
74,3 \\
2,4\end{array}$ & $\begin{array}{r}2429,3 \\
85,1 \\
50,1 \\
78,4 \\
2,4\end{array}$ & $\begin{array}{r}2708,3 \mathrm{~A} \\
95,3 \mathrm{~A} \\
78,2 \mathrm{~A} \\
89,6 \mathrm{~A} \\
2,5 \mathrm{~A}\end{array}$ & $\begin{array}{r}2395,6 \mathrm{~B} \\
82,6 \mathrm{~B} \\
52,5 \mathrm{~B} \\
76,3 \mathrm{~B} \\
2,4 \mathrm{~A}\end{array}$ & $\begin{array}{r}2545,6 \mathrm{a} \\
87,9 \mathrm{a} \\
69,4 \mathrm{a} \\
81,9 \mathrm{a} \\
2,4 \mathrm{a}\end{array}$ & $\begin{array}{r}2558,2 \mathrm{a} \\
90,0 \mathrm{a} \\
61,2 \mathrm{a} \\
84,1 \mathrm{a} \\
2,5 \mathrm{a}\end{array}$ \\
\hline $\begin{array}{l}\text { Eficiência mic. } \\
\text { Microbial effic. }\end{array}$ & & & & & & & & \\
\hline $\begin{array}{l}\mathrm{g} \mathrm{N}-\mathrm{mic} / \mathrm{kg} \text { MODRg } \\
\mathrm{N} \text {-mic/kg OMDR }\end{array}$ & 33,9 & 29,7 & 34,9 & 32,8 & $31,8 \mathrm{~A}$ & $33,9 \mathrm{~A}$ & $34,5 \mathrm{a}$ & $31,3 \mathrm{a}$ \\
\hline $\begin{array}{l}\text { g N-mic/Mcal EDRg } \\
N \text {-mic/Mcal EDR }\end{array}$ & 0,43 & 0,37 & 0,43 & 0,39 & $0,40 \mathrm{~A}$ & $0,41 \mathrm{~A}$ & $0,43 \mathrm{a}$ & $0,38 \mathrm{a}$ \\
\hline
\end{tabular}

$\mathrm{SM}=$ silagem de milho; $\mathrm{FE}=$ feno de tifton; SE = sem adição de enzimas; CE = com adição de enzimas. ${ }^{1} \mathrm{~kg} / \mathrm{dia} ;{ }^{2} \mathrm{~g} / \mathrm{dia} ;{ }^{3} \mathrm{Mcal} / \mathrm{dia}$.

Médias seguidas de letras diferentes na mesma linha, maiúscula para as fontes de volumoso (silagem de milho e feno de tifton) e minúscula para os níveis de enzima ( 0 e $12 \mathrm{~g} / \mathrm{animal} / \mathrm{dia})$, diferem $(\mathrm{P}<0,05)$ pelo teste Tukey.

$C S=$ corn silage; $T H=$ Tifton hay; $-E=$ without enzyme; $+E=$ with enzyme. ${ }^{1} \mathrm{~kg} /$ day; ${ }^{2} \mathrm{~g} /$ day; ${ }^{3} \mathrm{Mcal} /$ day .

Means followed by differentl letters in a row, capital letters to each roughage (corn silage and Tifton hay) and small letters to each enzyme level ( 0 and $12 \mathrm{~g} /$ animal/day), differ ( $P<0.05)$ by Tukey test. 
estudo sobre o efeito da suplementação com extratos do fungo Aspergillus orizae em novilhos pastejando gramínea de clima temperado (Bromus inermis), relataram aumento na eficiência de síntese microbiana e no fluxo de $\mathrm{N}$ microbiano para o duodeno com a suplementação.

Cecava et al. (1991), avaliando dietas com diferentes proporções de volumoso:concentrado, observaram redução na eficiência de síntese de proteína e aumento na quantidade de matéria orgânica fermentada no rúmen.

A fonte de volumoso teve efeito $(\mathrm{P}<0,05)$ sobre as variáveis avaliadas. As estimativas dos teores de $\mathrm{N}$ ingerido, MODR e EDR e os fluxos diários de MO, N microbiano (N-mic) e N não-amoniacal (NNA) foram superiores $(\mathrm{P}<0,05)$ nas dietas contendo silagem de milho em comparação àquelas contendo feno de tifton.

Estes resultados podem ser explicados pelas diferenças na composição química de ambos os volumosos, visto que a silagem apresenta menor teor de fibra e maior de proteína bruta, além de mais alto teor de carboidratos solúveis, conseqüência da fermentação ocorrida no silo. Portanto, estes fatores podem ter contribuído para o aumento do consumo de N, MODR e EDR e dos fluxos de MO, N-mic e NNA para o duodeno.

O valor médio observado para a MODR das dietas contendo silagem de milho foi de $2.612 \mathrm{~g} / \mathrm{dia}$, semelhante ao de $2.628 \mathrm{~g} /$ dia obtido por Fregadolli et al. (2001), que avaliaram uma dieta composta de silagem de milho, milho e levedura. Por outro lado, a EDR obtida para estas dietas $(7,47 \mathrm{Mcal} / \mathrm{dia})$ foi inferior à encontrada por Berchielli et al. (1995), de 8,86 Mcal/dia, ao estudarem uma dieta com relação volumoso:concentrado de 80:20.

O fluxo duodenal de $\mathrm{N}$ microbiano das dietas contendo feno apresentou valor médio de 52,5 g/dia, inferior ao obtido por Guimarães et al. (2001), de 100,6 g/dia, em estudo de uma dieta com relação volumoso:concentrado de 70:30, composta de feno de tifton e resíduo de mandioca. Esta diferença pode estar relacionada à fonte de amido da dieta. Segundo Zeoula et al. (2002), o fluxo de N microbiano pode aumentar quando o milho é substituído por uma fonte de amido mais degradável no rúmen, como a mandioca.

O valor médio do fluxo duodenal de NNA foi de $82,9 \mathrm{~g} /$ dia, inferior ao de 143,2 g/dia, obtido por Silveira (2001), como resultado do maior teor de PB da dieta $(13,6 \%)$ e, conseqüentemente, da maior ingestão de $\mathrm{N}$ (144,5 g/dia). O valor médio de eficiência de síntese microbiana neste estudo foi de 32,07 $\mathrm{g}$ de N-mic/kg de MODR, semelhante ao adotado pelo ARC (1984), de $32 \mathrm{~g}$ de N-mic/kg MODR, comprovando que o modelo utilizado proporcionou boa predição na estimativa dos parâmetros.
De acordo com Clark et al. (1992), o fluxo de N microbiano para o intestino delgado resulta, em parte, do maior teor de energia proveniente da matéria orgânica fermentada no rúmen. Entretanto, os autores observaram comportamento quadrático na relação fluxo de $\mathrm{N}$ microbiano e MODR e concluíram que outros fatores além da MODR estariam relacionados à eficiência de síntese microbiana, como a proporção de nutrientes na dieta e a sincronização da degradação dos alimentos que a compõem. Desta forma, a adição de enzimas às dietas não proporcionou aumento no teor de MODR nem alterou a sincronização da degradação dos alimentos, não havendo, portanto, efeito do complexo enzimático sobre a eficiência de síntese microbiana.

Yang et al. (1999) testaram a influência de três níveis de suplementação enzimática $(0,11$ g e 23 g) na cinética digestiva de vacas consumindo feno de alfafa e não verificaram efeito sobre a ingestão de $\mathrm{N}$ e o fluxo duodenal de NNA, mas notaram redução numérica da eficiência de síntese de proteína microbiana, de 30,3 (controle) para 27,9 g de N-mic/kg MODR, nos animais que receberam suplementação com 11 $\mathrm{g}$ de enzimas e aumento para 32,3 g de N-mic/kg MODR naqueles que receberam $23 \mathrm{~g}$ do suplemento.

Segundo Morgavi et al. (2000), as preparações de complexos enzimáticos comerciais são normalmente padronizadas de acordo com sua capacidade em degradar celulose ou xilana. Entretanto, estes produtos constituem compostos multienzimáticos que desempenham diferentes atividades fibrolíticas. Portanto, não há controle de qualidade sobre as outras enzimas, consideradas complemento, que poderiam alterar o desempenho de um complexo enzimático.

\section{Conclusões}

A adição de enzimas fibrolíticas ao feno de tifton e à silagem de milho não teve efeito sobre os parâmetros ruminais avaliados, exceto sobre a atividade da enzima $\beta$-1,4-endoglucanase, que aumentou com a adição de enzimas fibrolíticas ao feno de tifton.

\section{Literatura Citada}

AGRICULTURAL AND FOOD RESEARCH COUNCIL - AFRC. Technical committee on responses to nutrients: energy and protein requirements of ruminants. Wallinford: $C A B$ International, $1995.159 \mathrm{p}$.

AGRICULTURAL RESEARCH COUNCIL - ARC. Report of the protein group of the agricultural research council working party, on the nutrient requeriment of ruminants London: Commonwealth Agricultural Bureaux, 1984. 45p.

BEAUCHEMIN, K.A.; RODE, L.M.; SEWALT, J.H. Fibrolytic enzymes increase fiber digestibility and growth rate of steers fed dry forages. Canadian Journal of Animal Science, v.75, p.641-644, 1995. 
BEAUCHEMIN, K.A.; YANG, W.Z.; RODE, L.M. Effects of grain source and enzyme additive on site and extent of nutrient digestion on dairy cows. Journal of Dairy Science, v.82, p.378-390, 1999 .

BERCHIELLI, T.T.; RODRIGUEZ, N.M.; GONÇALVES, L.C. Eficiência de síntese de proteína microbiana estimada por diferentes marcadores microbianos. Revista Brasileira de Zootecnia, v.24, p.800-809, 1995.

CATON, J.S.; ERICKSON, D.O.; CAREY, D.A. et al. Influence of Aspergillus oryzae fermentation extract on forage intake, site of digestion, in situ degradability and duodenal amino acid flow in steers grazing cool-season pasture. Journal of Animal Science, v.71, p.779-787, 1993.

CECAVA, M.J.; MERCHEN, N.R.; GAY, L.C. Composition of ruminal bacteria harvested from steers as influenced by dietary energy level, feeding, frequency, and isolation techniques. Journal of Dairy Science, v.73, p.2480-2488, 1990.

CHESSON, A. Feed enzymes. Animal Feed Science and Technology, v.45, p.65-79, 1993

CLARK, J.H.; KLUSMEYER, T.H.; CAMERON, M.R. Microbial protein synthesis and flows of nitrogen fractions to the duodenum of dairy cows. Journal of Dairy Science, v.75, p.2304-2323, 1992.

FREGADOLLI, F.L.; ZEOULA, L.M.; PRADO, I.N. et al. Efeito das fontes de amido e nitrogênio de diferentes degradabilidades ruminais. 1. Digestibilidades parcial e total. Revista Brasileira de Zootecnia, v.30, p.858-869, 2001.

FENG, P.; HUNT, C.W.; PRITCHARD, G.T. et al. Effect of enzyme preparations on in situ and in vitro degradation and in vivo digestive characteristics of mature cool-season grass forage in beef steers. Journal of Animal Science, v.74, p.1349-1357, 1996.

GUIMARÃES, K.C.; BRANCO, A.F.; ALCALDE, C.C. et al. Efeito do período experimental sobre a fermentação e eficiência de síntese microbiana em bovinos alimentados com dois níveis de volumosos. Revista Brasileira de Zootecnia, v.30, p.880$887,2001$.

HRISTOV, A.N.; McALLISTER, T.A.; CHENG, K.-J. Intraruminal supplementation with increasing levels of exogenous polisacharide-degrading enzymes: effects on nutrient digestion in cattle feed barley grain diets. Journal of Animal Science, v.78, p.477-487, 2000 .

HUNT, C.W.; FENG, P.; TREACHER, R. et al. Effect of fibrolytic enzyme additives on in vitro degradability of alfafa and tall fescue. Journal of Animal Science, v.73, p.341 (Abstr.), 1995 (suppl.1).

LEWIS, G.E.; HUNT, C.W.; SANCHEZ, W.K. et al. Effect of directfed fibrolytic enzymes on the digestive characteristics of a forage-based diet fed to beef steers. Journal of Animal Science, v.74, p.3020-3028, 1996.

McALLISTER, T.A.; HRISTOV, A.N.; BEAUCHEMIN, K.A. et al. Enzymes in ruminant diets. In: BEDFORD, M.R.; PARTRIDGE, G.G. (Eds.). Enzymes in farm nutrition. Oxon: Cab International, 2001. p.273-298.
MICHALET-DOREAU, B.; FERNANDES, I.; PEYRON, C. et al Fibrolytic activities and cellulolytic bacterial community structure in the solid and liquid phases of rúmen contents. Reproduction Nutrition Development, v.41, p.187-194, 2001.

MORGAVI, D.P.; BEAUCHEMIN, K.A.; NSEREKO, V.L. Synergy between ruminal fibrolytic enzymes and enzymes from Trichoderma longibrachiatum. Journal of Dairy Science, v.83, p.1310-1321, 2000.

NATIONAL RESEARCH COUNCIL - NRC. Nutrient requeriments of beef cattle. 7.ed. Washington, D.C.: National Academy Press, 1996. 381p.

STATISTICAL ANALYSES SYSTEM - SAS. Users' guide: statistics. 5.ed. Cary: 1985. v.1, 956p.

SCHINGOETHE, D.J.; STEGEMAN, G.A.; TREACHER, R.J. Response of lactanting dairy cows to a cellulase and xylanase enzyme mixture applied to forages at the time of feeding. Journal of Dairy Science, v. 82, p.996-1003, 1999.

SILVA, D.J. Análise de alimentos (Métodos químicos e biológicos). Viçosa, MG: Universidade Federal de Viçosa, 1990. 165p.

SILVEIRA, R.N. Avaliação nutricional de silagens de resíduos de mandioca e de cana-de-açúcar, com polpa cítrica, para bovinos. Jaboticabal: Universidade Estadual Paulista, 2001. 48p. Dissertação (Mestrado em Zootecnia) - Universidade Estadual Paulista, 2001.

USHIDA, K.; LASSALAS, B.; JOUANY, J.P. Determination of assay parameters for RNA analysis in bacterial and duodenal samples by spectrophotometry. Influence of sample treatment and preservation. Reprodution Nutrition Development, v.25, p.1037-1046, 1985.

VALADARES, R.F.D. Níveis de proteína em dieta de bovinos: consumo, digestibilidade, eficiência de síntese microbiana, amônia ruminal, uréia plasmática e excreções de uréia e creatinina. Belo Horizonte: Universidade Federal de Minas Gerais, 1997. 101p. Tese (Doutorado em Ciência Animal) - Universidade Federal de Minas Gerais, 1997.

Van SOEST, P.J. Nutritional ecology of the ruminant. 2.ed. Ithaca: Comstock Publication Association, 1994. 476p.

WALLACE, R.J.; WALLACE, S.J.A.; McKAIN, N. Influence of supplementary fibrolytic enzymes on the fermentation of corn and grass silages by mixed ruminal microorganims in vitro. Journal of Animal Science, v.79, p.1905-1916, 2001.

ZEOULA, L.M.; CALDAS NETO, S.; FREGADOLLI, F.L. et al. Mandioca e resíduos das farinheiras na alimentação de ruminantes: $\mathrm{pH}$, concentração de $\mathrm{N}-\mathrm{NH}_{3}$ e eficiência microbiana. Revista Brasileira de Zootecnia, v.31, p.1582-1593, 2002. 